Engineering and Computational Mechanics Volume 164 Issue EM2

FE homogenised limit analysis model Milani and Lourenço
Proceedings of the Institution of Civil Engineers Engineering and Computational Mechanics 164 June 2011 Issue EM2 Pages 65-78 doi: 10.1680/eacm.2011.164.2.65 Paper 900019 Received 24/03/2009 Accepted 29/09/2009 Keywords: brickwork \& masonry/failures/mathematical modelling

\title{
FE homogenised limit analysis model for masonry structures
}

1 Gabriele Milani MSc, PhD

Assistant Professor, Dipartimento di Ingegneria Strutturale (DIS), Politecnico di Milano, Milano, Italy
2 Paulo B. Lourenço MSc, PhD

Professor, Department of Civil Engineering (DEC), University of Minho, Azurém, Guimarães, Portugal
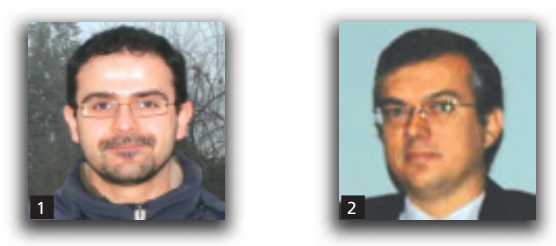

A finite-element (FE) homogenised limit analysis model suitable for analysing masonry structures near collapse is applied to a real large-scale three-dimensional (3D) masonry building subjected to horizontal actions. In the model, masonry is substituted for a fictitious macroscopic homogeneous material. Masonry macroscopic mechanical properties are obtained by means of a recently presented equilibrated limit analysis approach performed on a suitable unit cell, which generates the entire structure by repetition. Masonry homogenised failure surfaces are then implemented in the 3D code outlined. With respect to previously presented models, the software allows analysis of real-scale buildings without the classic uncoupling of in-plane and out-of-plane actions. The possible presence of steel, reinforced concrete and ring beams is also considered by introducing two-node beam elements in the numerical model. A relevant 3D structural example (a masonry structure subjected to horizontal actions) is treated. Full sensitivity analyses and comparison with results obtained from commercial elasto-plastic software are also presented to validate the results of the proposed model.

\section{Introduction}

The evaluation of the ultimate load-bearing capacity of masonry buildings subjected to horizontal loads is a fundamental task in their design or safety assessment. Practitioners usually adopted simplified limit analysis methods for safety analyses and design of strengthening (Giuffrè, 1993), but many codes of practice (e.g. Italian OPCM 3274 (OPCM, 2003) and 3431 (OPCM, 2005)) require static non-linear analyses for existing masonry buildings. In such analyses, limited ductile behaviour of the elements is taken into account, featuring failure mechanisms such as rocking, shear and diagonal cracking of walls.

Many researchers have proposed a number of different numerical approaches (see Lourenço (2002) for a comprehensive review) based on micro-modelling, macro-modelling or homogenisation, with the aim of obtaining reliable tools to predict masonry behaviour at failure. However, heterogeneous approaches (e.g. Lourenço and Rots, 1997) based on a distinct representation of bricks and joints seem limited to the study of panels of small dimensions due to the large number of variables involved in nonlinear finite-element (FE) analysis. On the other hand, strategies based on macro-modelling (e.g. Lourenço et al., 1997) have the drawback of requiring preliminary mechanical characterisation of a model usually obtained from experimental data fitting.
The work reported here focuses exclusively on the collapse analysis of masonry structures, making use of homogenisation techniques. Such an approach is based on the substitution of the heterogeneous material by a fictitious homogeneous one, with mechanical properties calibrated on a representative element of volume that generates the entire structure by repetition. For this reason, this seems to be the only approach suitable for a largescale FE analysis. Furthermore, the application of homogenisation theory to the rigid-plastic case (Suquet, 1983) is particularly suited to a simple but reliable structural analysis, requiring only a reduced number of material parameters and providing significant information at failure such as limit multipliers, collapse mechanisms and - at least on critical sections - the stress distribution (Milani et al., 2006b).

This paper presents the final result of research work followed by the authors for the implementation and validation of a homogenised limit analysis code to be used by practitioners for the FE limit analysis of entire masonry buildings subjected to seismic static loads. The research started with an analysis of in-plane loaded structures (Milani et al., 2006a, 2006b) and proceeded with extension of the model to out-of-plane actions (Milani et al., 2006c) and successive generalisation to small three-dimensional (3D) masonry houses. 
While in previous work (Milani et al., 2007) only the analysis of small-scale structures with few elements was possible, this work considers a large 3D masonry building in which both plate and shell (masonry) and beam (or truss) elements interact. A userfriendly CAD interface for data pre- and post-processing has been implemented. At present, in the code:

(a) a quick graphical insertion of single elements is possible

(b) an auto-meshing tool for triangular elements is implemented

(c) masonry walls with different mechanical properties (e.g. different thickness, different materials) can be handled

(d) one-dimensional (1D) and two-dimensional (2D) reinforced concrete ( $\mathrm{RC}$ ) elements can be inserted

(e) a robust interior point linear programming (LP) algorithm is implemented in order to solve large-scale sparse problems with many FEs.

The final aim at the base of such improvements is the distribution of the software to practitioners interested in the safety assessment of complex real masonry buildings.

A pre-processing phase is present in the software that allows one sensitivity and parametric analyses, thus giving the designer the possibility of checking the hypotheses adopted for the mechanical properties of the constituent materials and the role played by the structural elements.

\section{In- and out-of-plane masonry homogenised failure surfaces}

In order to estimate masonry macroscopic failure surfaces, homogenisation concepts are hereafter applied. For the constituent materials (bricks and mortar), rigid perfectly plastic behaviour with associated flow rule is assumed.

Let $S^{\mathrm{m}}, S^{\mathrm{b}}$ and $S^{\text {hom }}$ denote respectively the strength domains of mortar, units and homogenised macroscopic material. It has been shown by Suquet (1983) in a general framework that $S^{\text {hom }}$ can be obtained by means of a so-called static approach in which the variables to handle are the stresses on the unit cell (hereafter called micro-stresses). The authors recently proposed (Milani et al., 2006a, 2006c) a simplified procedure to obtain homogenised in- and out-of-plane failure surfaces $S^{\text {hom }}$ for masonry. In particular, $S^{\text {hom }}$ was derived by means of the following (nonlinear) optimisation problem:

$$
\left.S^{\mathrm{hom}}=\left\{\max (M, N) \mid \begin{array}{cc}
N=\frac{1}{|Y|} \int_{Y \times h} \boldsymbol{\sigma} \mathrm{d} V & \text { (a) } \\
M=\frac{1}{|Y|} \int_{Y \times h} y_{3} \boldsymbol{\sigma} \mathrm{d} V & \text { (b) } \\
\operatorname{div} \boldsymbol{\sigma}=\mathbf{0} & \text { (c) } \\
{[[\boldsymbol{\sigma}]] \mathbf{n}^{\text {int }}=\mathbf{0}} & \text { (d) } \\
\boldsymbol{\sigma} \mathbf{n} \text { anti-periodic on } \partial Y_{l} & \text { (e) } \\
\boldsymbol{\sigma}(\mathbf{y}) \in S^{\mathrm{m}} \quad \forall \mathbf{y} \in Y^{\mathrm{m}} ; \boldsymbol{\sigma}(\mathbf{y}) \in S^{\mathrm{b}} \quad \forall \mathbf{y} \in Y^{\mathrm{b}} & \text { (f) }
\end{array}\right\}\right\}
$$

to recover, with an admissible and equilibrated approach, masonry homogenised in- and out-of-plane failure surfaces. In particular, in the model, the elementary cell is sub-divided along its thickness in several layers. For each layer, fully equilibrated stress fields are assumed, adopting polynomial expressions for the stress tensor components in a finite number of sub-domains. The continuity of the stress vector on the interfaces between adjacent sub-domains and suitable anti-periodicity conditions on the boundary surface are further imposed. In this way, linearised homogenised surfaces in six dimensions for masonry in- and outof-plane loads are obtained.

In order to show the capabilities of the package developed at this stage, a relevant 3D structural example (a masonry school subjected to horizontal actions) is treated. Full sensitivity analyses and a comparison with results obtained with commercial elasto-plastic software are also presented as validation.

Due to the very limited computational effort required by the FE limit analysis with respect to traditional non-linear approaches (only a few minutes are needed to solve the optimisation problem instead of hours of processing time), the model allows full where $N$ and $M$ are the macroscopic in-plane (membrane forces) and out-of-plane (bending moments and torsion) tensors; $\boldsymbol{\sigma}$ denotes the microscopic stress tensor; $\mathbf{n}$ is the outward versor of $\partial Y_{l}$ surface (see Figure 1(a)); [[б]] is the jump of micro-stresses across any discontinuity surface of normal $\mathbf{n}^{\text {int }}$ (Figure 1(c)); $S^{\mathrm{m}}$ and $S^{\mathrm{b}}$ denote respectively the strength domains of mortar and bricks; $Y$ is the cross-section of the 3D elementary cell with $y_{3}=0$ (see Figure 1), $|Y|$ is its area, $V$ is the elementary cell volume, $h$ is wall thickness and $\mathbf{y}=\left(\begin{array}{lll}y_{1} & y_{2} & y_{3}\end{array}\right)$ are the assumed material axes; and $Y^{\mathrm{m}}$ and $Y^{\mathrm{b}}$ represent mortar joints and bricks, respectively, see Figure 1 .

It is worth noting that anti-periodicity conditions (Equation 1(e)) require that stress vectors $\boldsymbol{\sigma} \mathbf{n}$ are opposite on opposite sides of $\partial Y_{l}$ (Figure 1(c)), that is $\sigma^{(m)} \mathbf{n}_{1}=-\sigma^{(n)} \mathbf{n}_{2}$

In previous work by the authors (Milani et al., 2006b), the unit cell was sub-divided into a fixed number of layers along its thickness, as shown in Figure 1(b). For each layer, out-of-plane components $\sigma_{i 3}(i=1,2,3)$ of the micro-stress tensor $\boldsymbol{\sigma}$ were set to zero, so that only in-plane components $\sigma_{i j}(i, j=1,2)$ were considered active. Furthermore, $\sigma_{i j}(i, j=1,2)$ were kept 

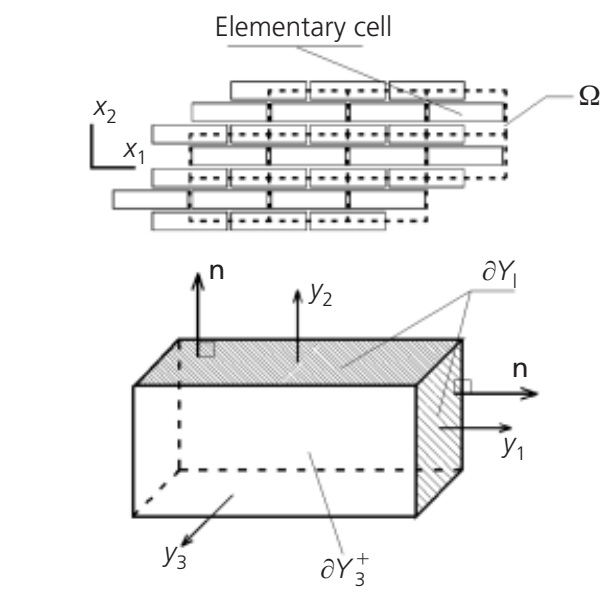

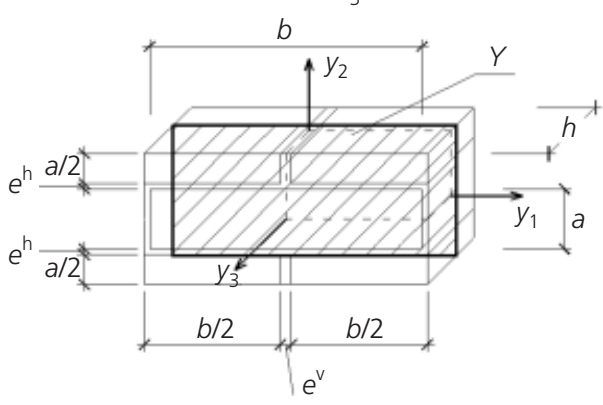

(a)

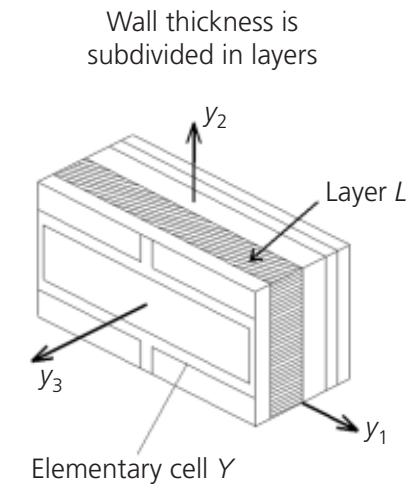

Each layer is subdivided in 36 sub-domains

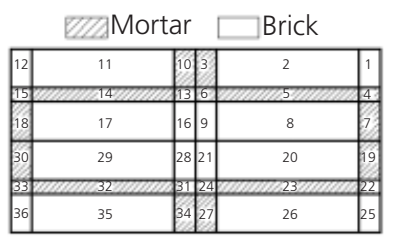

Imposition of internal equilibrium, equilibrium on

interfaces and anti-periodicity
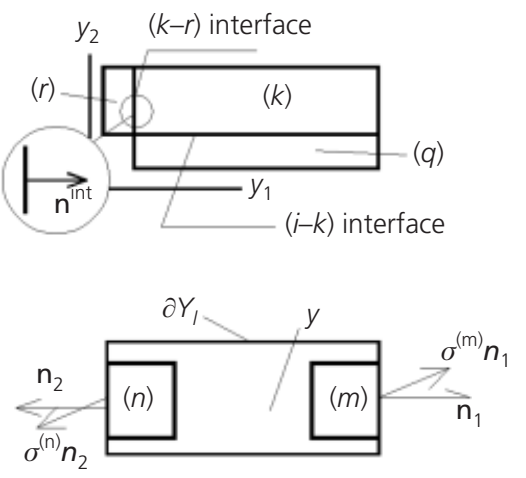

(b)

(c)

Figure 1. Proposed micro-mechanical model: (a) elementary cell; (b) sub-division in layers along thickness and sub-division of each layer in sub-domains; (c) imposition of internal equilibrium, equilibrium on interfaces and anti-periodicity

constant along the $\Delta_{L}$ thickness of each layer $L$ (i.e. in each layer $\left.\sigma_{i j}=\sigma_{i j}\left(y_{1}, y_{2}\right)\right)$. For each layer in the wall thickness direction, one-quarter of the representative volume element was sub-divided into nine geometrical elementary entities (sub-domains), so that the entire elementary cell was sub-divided into 36 sub-domains (see Figure 1(b) and Milani et al. (2006a)).

For each sub-domain $k$ and layer $L$, polynomial distributions of degree $m$ in the variables $\left(y_{1}, y_{2}\right)$ were a priori assumed for the stress components. Since stresses were polynomial expressions, the generic $i j$ th component was written as

$$
\text { 2. } \sigma_{i j}^{(k, L)}=\mathbf{X}(\mathbf{y}) \mathbf{S}_{i j}^{(k, L) \mathrm{T}} \quad \mathbf{y} \in Y^{(k, L)}
$$

$$
\begin{aligned}
\text { where } \mathbf{X}(\mathbf{y})= & {\left[\begin{array}{lllllll}
1 & y_{1} & y_{2} & y_{1}^{2} & y_{1} y_{2} & y_{2}^{2} & \ldots
\end{array}\right], } \\
\mathbf{S}_{i j}^{(k, L)}= & {\left[\begin{array}{lllll}
S_{i j}^{(k, L)(1)} & S_{i j}^{(k, L)(2)} & S_{i j}^{(k, L)(3)} & \\
& S_{i j}^{(k, L)(4)} & S_{i j}^{(k, L)(5)} & S_{i j}^{(k, L)(6)} & \ldots
\end{array}\right] }
\end{aligned}
$$

is a vector representing the unknown stress parameters of subdomain $k$ of layer $L$ and $Y^{(k, L)}$ represents the $k$ th sub-domain of layer $L$.

The imposition of equilibrium inside each sub-domain, the continuity of the stress vector on interfaces and the antiperiodicity of $\boldsymbol{\sigma n}$ permitted a reduction in the number of independent stress parameters (Milani et al., 2006a).

Assemblage operations on the local variables allows writing the stress vector $\tilde{\boldsymbol{\sigma}}^{(k, L)}$ of layer $L$ inside each sub-domain as

$$
\begin{aligned}
\tilde{\boldsymbol{\sigma}}^{(k, L)}= & \tilde{\mathbf{X}}^{(k, L)}(\mathbf{y}) \tilde{\mathbf{S}}^{(L)} \\
& (k=1, \ldots, \text { no.of sub-domains; } \\
& L=1, \ldots, \text { no of layers })
\end{aligned}
$$

where $\tilde{\mathbf{S}}^{(L)}$ is a $N_{\mathrm{uk}} \times 1$ ( $N_{\mathrm{uk}}=$ number of unknowns per layer $)$ vector of linearly independent unknown stress parameters of layer $L$ and $\tilde{\mathbf{X}}^{(k, L)}(\mathbf{y})$ is a $3 \times N_{\mathrm{uk}}$ matrix depending only on the 
geometry of the elementary cell and on the position $\mathbf{y}$ of the point in which the micro-stress is evaluated.

\section{Basics of the 3D kinematic FE limit analysis approach proposed}

The homogenised masonry strength domain obtained with the simple model summarised in Section 2 is implemented in a novel and optimised 3D kinematic FE limit analysis code for failure analysis of entire buildings. The upper bound approach proposed here is based both on the formulation presented by Sloan and Kleeman (1995) for the in-plane case and on the formulation of Munro and Da Fonseca (1978) for out-of-plane actions. The formulation uses three-node triangular elements with linear interpolation of the velocity field inside each element, so that three velocity unknowns per node $i$, say $w_{x x}^{i}, w_{y y}^{i}$ and $w_{z z}^{i}$ (two inplane velocities and one out-of-plane velocity, respectively; see Figure 2(a)) are introduced for each element $E$, meaning that the velocity field is linear inside an element, whereas the strain rate field is constant for in-plane actions.

For the sake of simplicity, it is assumed that jump of velocities on interfaces occurs only in the plane containing two contiguous and coplanar elements, with linear interpolation of the jump along the interface. Hence, for each interface between coplanar adjacent elements, four additional unknowns are introduced $\left(\Delta \mathbf{u}^{I}=\left[\begin{array}{lll}\Delta v_{1} \Delta u_{1} \Delta v_{2} \Delta u_{2}\end{array}\right]^{\mathrm{T}}\right)$, representing the normal $\left(\Delta v_{i}\right)$ and tangential $\left(\Delta u_{i}\right)$ jumps of velocities (with respect to the discontinuity direction) evaluated on nodes $i=1$ and $i=2$ of the interface (see Figure 2(b)). Hence, for any pair of nodes on the interface between two adjacent and coplanar triangles $R$ and $K$ (Figure 2(c)), the tangential and normal velocity jumps can be written in terms of the Cartesian nodal velocities of elements $R-K$, so that four linear equations of the form $\mathbf{A}_{11}^{\mathrm{eq}} \mathbf{w}^{R}+\mathbf{A}_{12}^{\mathrm{eq}} \mathbf{w}^{K}+\mathbf{A}_{13}^{\mathrm{eq}} \Delta \mathbf{u}^{I}=\mathbf{0}$ can be written, where $\mathbf{w}^{R}$ and $\mathbf{w}^{K}$ are the $9 \times 1$ vectors that collect velocities of elements $R$ and $K$ respectively and $\mathbf{A}_{1 j}^{\mathrm{eq}} j=1,2,3$ are matrices that depend only on the interface orientation $\Omega^{I}$.

Under in-plane loads, three equality constraints representing plastic flow in the continuum (obeying an associated flow rule) are introduced for each element in the form $\dot{\boldsymbol{\varepsilon}}_{\mathrm{pl}}^{E}=\dot{\lambda}^{E} \partial S^{\text {hom }} / \partial \Sigma$, where $\dot{\varepsilon}_{\mathrm{pl}}^{E}$ is the plastic strain rate vector of element $E, \dot{\lambda}^{E} \geqslant 0$ is the plastic multiplier, $S^{\text {hom }}$ is the homogenised (non) linear failure surface of masonry and $\Sigma$ is the vector of macroscopic variables $\Sigma=\left(N_{11}, N_{12}, N_{22}, M_{11}, M_{12}, M_{22}\right)$.

From the previous section, a linear approximation (with $m$ hyperplanes) of the failure surface in the form $S^{\text {hom }} \equiv \mathbf{A}^{\text {in }} \Sigma \leqslant \mathbf{b}^{\text {in }}$ is considered, where $\mathbf{A}^{\text {in }}$ is a $m \times 6$ matrix of coefficients of each hyper-plane and $\mathbf{b}^{\text {in }}$ is a $m \times 1$ vector of the right-hand sides of the linear approximation. Note that three linear equality constraints per element can be written $\left(\mathbf{A}_{11}^{\mathrm{eq}} \mathbf{w}^{E}+\mathbf{A}_{12}^{\mathrm{eq}} \dot{\lambda}^{E}=\mathbf{0}\right.$, where $\mathbf{w}^{E}$ is the vector of element velocities and $\dot{\lambda}^{E}$ is a $m \times 1$ vector of plastic multiplier rates, one for each plane of the linearised failure surface).
Masonry elements plate and shell triangle

(E) element

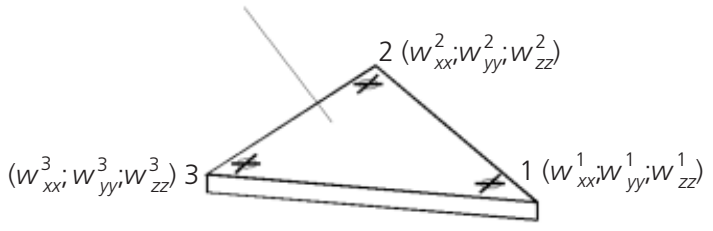

(a)

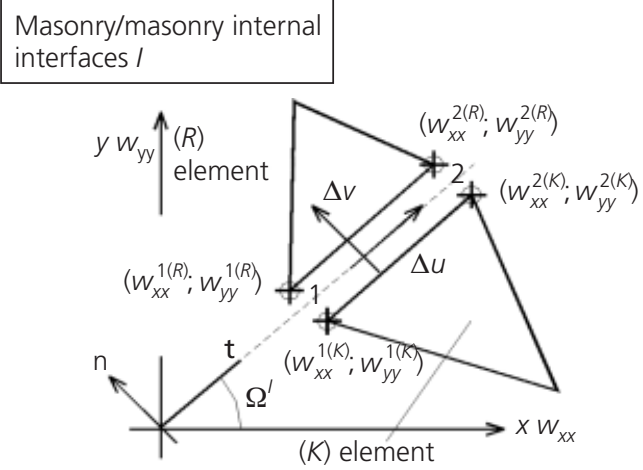

$\mathrm{n}$ : normal to the interface

(b)

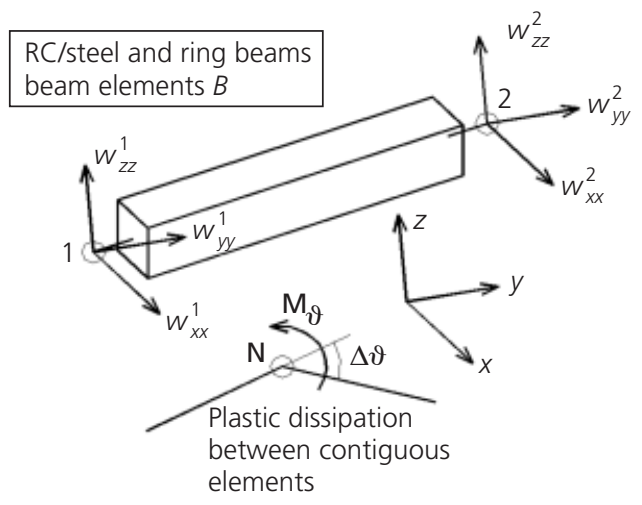

(c)

Figure 2. (a) Triangular plate and shell element used for the upper bound FE limit analysis. (b) Discontinuity of the in-plane velocity field. (c) Finite elements used to model ring beams and steel/RC beams

Due to the linear interpolation of the velocity field, out-of-plane plastic dissipation occurs only along each interface $I$ between two adjacent triangles $R$ and $K$ or on a boundary side $B$ of an element $Q$ (see Figure 3). Denoting by $\mathbf{w}_{z z, E}=$ $\left[\begin{array}{lll}w_{z z}^{i(E)} & w_{z z}^{j(E)} & w_{z z}^{k(E)}\end{array}\right]^{\mathrm{T}}$ the element $E$ out-of-plane nodal velocities and by $\dot{\boldsymbol{\theta}}_{E}=\left[\begin{array}{lll}\dot{\vartheta}_{i}^{E} & \dot{\vartheta}_{j}^{E} & \dot{\vartheta}_{k}^{E}\end{array}\right]^{\mathrm{T}}$ the side normal rotation rates, it is possible to show that $\dot{\boldsymbol{\theta}}_{E}$ and $\mathbf{w}_{z z, E}$ are linked by the 

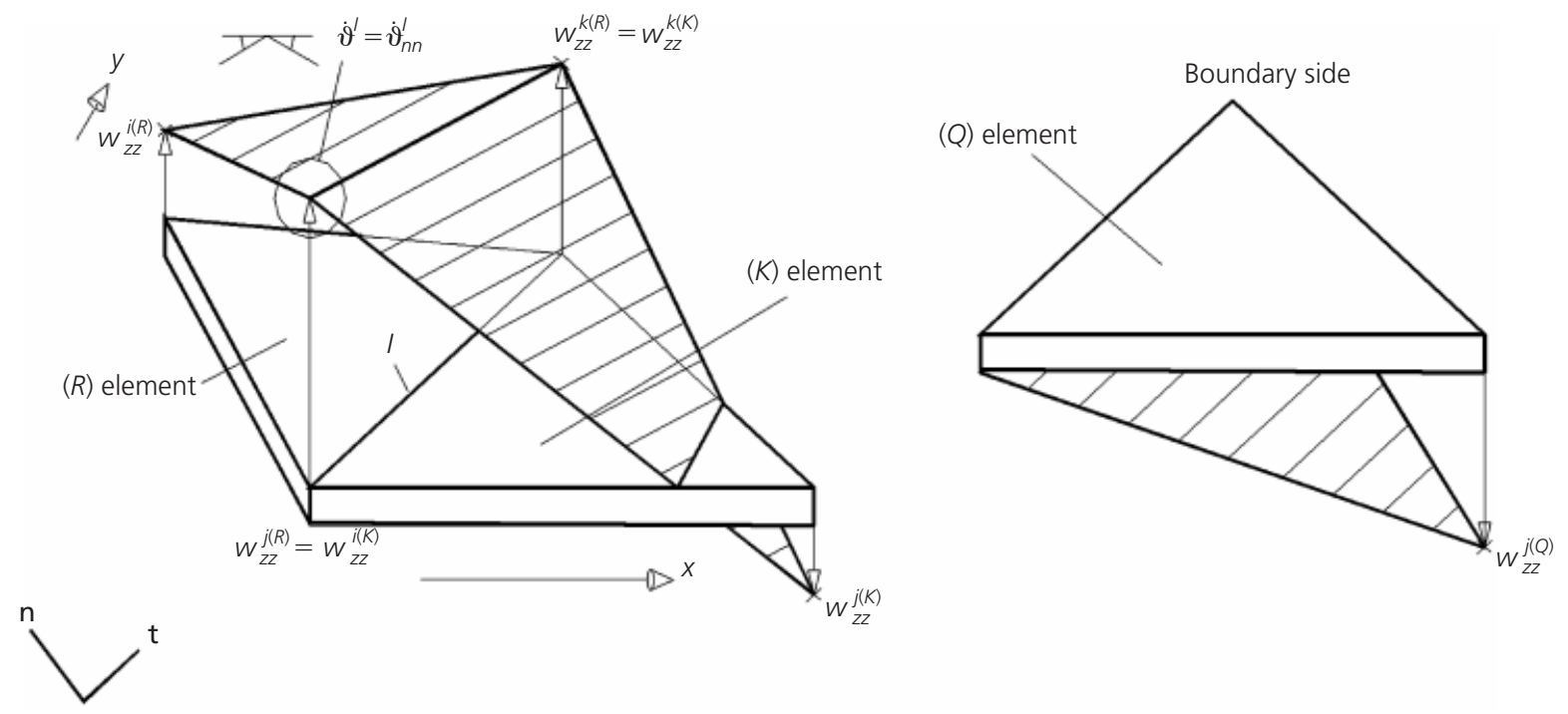

Figure 3. Rotation rate along an interface between adjacent triangles or in correspondence of a boundary side

compatibility equation (Figure 3) $\dot{\boldsymbol{\theta}}_{E}=\mathbf{B}_{E} \mathbf{w}_{z z, E}$, where $\mathbf{B}_{E}$ is a $3 \times 3$ matrix that depends only on the geometry of element $E$.

The total internal power dissipated $P^{\text {in }}$ is constituted by the power dissipated in continuum, $P_{E}^{\text {in }}$, and the power dissipated on interfaces, $P_{I}^{\text {in }} . P_{E}^{\text {in }}$ can be evaluated for each triangle $E$ of area $A_{E}$ taking into account that curvature rates $\dot{\chi}_{x x}, \dot{\chi}_{x y}, \dot{\chi}_{y y}$ are zero in continuum, so that the flexural part of the model does not dissipate power in the continuum.

For interface $I$ of length $\Gamma$ and orientation $\Omega^{I}$, a rotation operator is applied to the linearised homogenised failure surface in order to obtain, with a few row operations, $m$ equations (one for each hyperplane representing the homogenised failure surface $\tilde{S}^{\text {hom }}$ in the $\mathbf{n}-\mathbf{t}$ interface frame of reference (Figure 2(b)). Therefore, the power dissipated $P_{I}^{\text {in }}$ along interface $I$ of length $\Gamma$ and with orientation $\Omega^{I}$ can be estimated as $P_{I}^{\text {in }}=\int_{\Gamma} \sum_{q=1}^{m} C_{I}^{q} \dot{\lambda}_{I}^{(q)}(\xi) \mathrm{d} \xi$, where $\dot{\lambda}_{I}^{(q)}(\xi)$ represents the $q$ th plastic multiplier rate of a point $\xi$ of the interface $I$ and $C_{I}^{q}$ is the right-hand side of the $q$ th linearisation plane of the homogenised failure surface of the interface.

In the model, the possible presence of ring and $\mathrm{RC} /$ steel beams is also considered through the utilisation of suitable two-node beam elements (Figure 2(c)). A linear interpolation of the velocity field inside the elements is adopted. Thus, plastic dissipation inside each beam is due only to normal action (compression or tension), whereas flexural dissipation occurs only at the interfaces between adjoining elements. No dissipation occurs for torsion. For the sake of simplicity, we suppose that ultimate axial load $N_{\mathrm{u}}^{+/-}$ $(+$, tension; -, compression) and bending moments along perpendicular principal directions of the beam section $\left(M_{\mathrm{u} \xi}\right.$ and $\left.M_{\mathrm{u} \eta}\right)$ are uncoupled. Therefore internal plastic dissipation on beam elements is given by a contribution of the element $\left(P_{B}^{\mathrm{in}}\right)$ due to $N_{\mathrm{u}}$ and a contribution of the plastic hinge between two elements $\left(P_{N}^{\text {in }}\right)$ due to $M_{\mathrm{u}}$.

Concerning external power dissipation, no differences occur with respect to classic FE limit analysis codes. External power dissipated can be written as $P^{\mathrm{ex}}=\left(\mathbf{P}_{0}^{\mathrm{T}}+\lambda \mathbf{P}_{1}^{\mathrm{T}}\right) \mathbf{w}$, where $\mathbf{P}_{0}$ is the vector of (equivalent lumped) permanent loads, $\lambda$ is the load multiplier for the structure examined, $\mathbf{P}_{1}^{\mathrm{T}}$ is the vector of (lumped) variable loads and $\mathbf{w}$ is the vector of assembled nodal velocities. As the amplitude of the failure mechanism is arbitrary, a further normalisation condition $\mathbf{P}_{1}^{\mathrm{T}} \mathbf{w}=1$ is usually introduced. Hence, the external power becomes linear in $\mathbf{w}$ and $\lambda$ (i.e. $P^{\mathrm{ex}}=\mathbf{P}_{0}^{\mathrm{T}} \mathbf{w}+\lambda$ ).

After some assemblage operations (not reported here for the sake of brevity), the following LP problem is obtained (analogous to that reported by Krabbenhoft et al. (2005)) where the objective function consists of minimisation of the total internal power dissipated

$$
\min \left\{\sum_{I=1}^{n^{I}} P_{I}^{\mathrm{in}}+\sum_{E=1}^{n^{E}} P_{E}^{\mathrm{in}}-\mathbf{P}_{0}^{\mathrm{T}} \mathbf{w}\right\}
$$

such that

$$
\left\{\begin{array}{c}
\mathbf{A}^{\mathrm{eq}} \mathbf{U}=\mathbf{b}^{\mathrm{eq}} \\
\dot{\lambda}^{I, \text { ass }} \geqslant \mathbf{0} \quad \dot{\lambda}^{E, \text { ass }} \geqslant \mathbf{0} \\
\dot{\boldsymbol{\theta}}^{\text {ass }}=\dot{\boldsymbol{\theta}}^{+}-\dot{\boldsymbol{\theta}}^{-} \\
\dot{\boldsymbol{\theta}}^{+} \geqslant 0 \quad \dot{\boldsymbol{\theta}}^{-} \geqslant 0
\end{array}\right.
$$


where $\mathbf{U}$ is the vector of global unknowns, and collects the vector of assembled nodal velocities (w), the vector of assembled element plastic multiplier rates $\left(\dot{\boldsymbol{\lambda}}^{E \text {,ass }}\right)$, the vector of assembled jump of velocities on interfaces $\left(\Delta \mathbf{u}^{I, \text { ass }}\right)$, the vector of assembled interface plastic multiplier rates $\left(\dot{\lambda}^{I, \text { ass }}\right)$ and the vector of interface and boundary out-of-plane rotation angles $\dot{\boldsymbol{\theta}}^{\text {ass }} . \mathbf{A}^{\mathrm{eq}}$ is the overall constraints matrix and collects normalisation conditions, velocity boundary conditions, relations between velocity jumps on interfaces and elements velocities, constraints for plastic flow in velocity discontinuities and constraints for plastic flow in continuum. $n^{E}$ and $n^{I}$ are the total number of elements and interfaces, respectively.

It is worth underlining some important limitations of the limit analysis model proposed for the study of masonry structures. In particular, a typical drawback of this approach is its inability to predict displacements at collapse. Moreover, an infinite plastic deformation capacity of the material at hand is assumed: this hypothesis should be checked, depending on the geometry of the masonry wall and the distribution of loads applied. In particular, masonry walls exhibiting rocking failure modes or shear failure modes usually present a significantly ductile response. Finally, when collapses are mostly related to sliding, masonry could fail with a typical frictional behaviour; this should be rigorously represented through the assumption of nonassociated flow rules for the constituent materials. However, when non-associativity is considered, mixed complementarity problems should be tackled, requiring relatively sophisticated algorithms to be solved and allowing handling of problems with fewer variables. On the other hand, many works (e.g. Cecchi and Milani, 2008; Heyman, 1969; Sinha 1978) have demonstrated that very reasonable results can be obtained even with
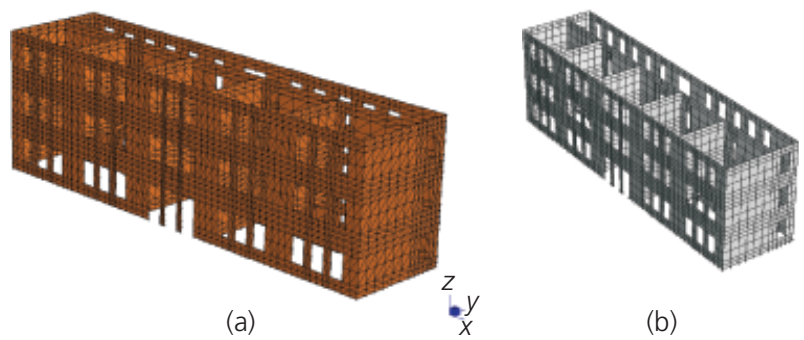

(b)

Figure 4. Entire masonry building subjected to horizontal actions. (a) Mesh used for the limit analysis (6304 triangular elements, 618 beams, 3627 nodes). (b) Mesh used in strand 7 for an elastoplastic analysis with Mohr-Coulomb failure criterion (3152 plate elements)

associated flow rules for the constituent materials, in almost all cases. For this reason and with the aim of tackling large-scale engineering problems through simple LP routines, classic theorems of limit analysis are adopted here.

\section{Failure load prediction of a 3D masonry structure}

The example given here is the prediction of the horizontal failure load of a real three-storey masonry building located in Italy (Figure 4). The building is a school in the north-east of Italy built at the end of nineteenth century in an isolated position and consisting of two structurally independent rectangular main bodies, as can be seen in the plan view shown in Figure 5.

The main building, called here for the sake of simplicity body A, is a rectangular shape of dimensions $L_{1} \times L_{2}=49.0 \times 12.2 \mathrm{~m}^{2}$ and comprising three storeys; the secondary building (body B) is

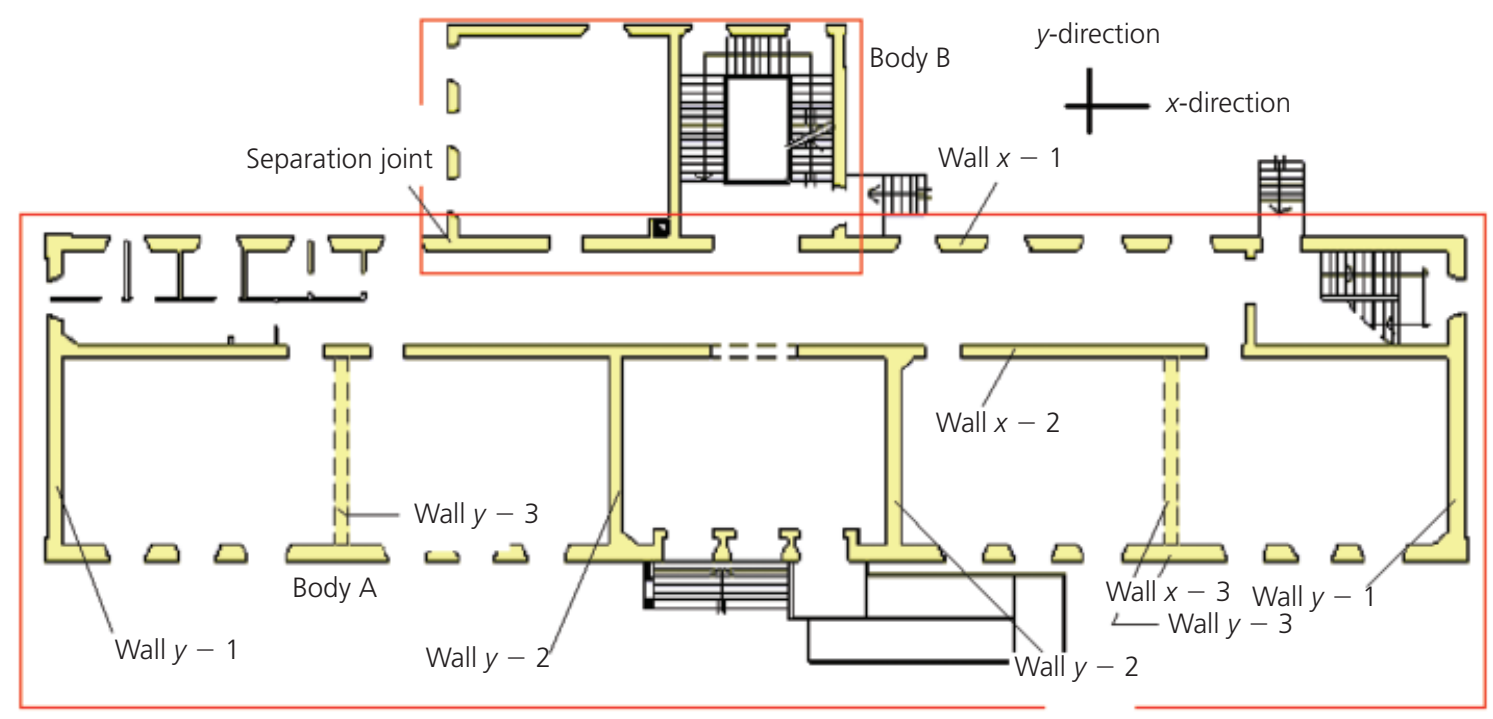

Figure 5. First floor plan view, masonry building subjected to

horizontal action 
also rectangular $\left(L_{1} \times L_{2}=8 \times 13 \mathrm{~m}^{2}\right)$, again with three storeys. All the walls are made of clay bricks, assumed to be of dimensions $250 \times 120 \times 55 \mathrm{~mm}^{3}$ (length $\times$ width $\times$ height) in the absence of precise information. The first storey height is $4.85 \mathrm{~m}$, and the second and third storeys are $4.65 \mathrm{~m}$ high.

A rehabilitation programme was carried out during the 1980s. On that occasion, several bearing walls at ground floor level were removed and replaced by steel beams at first floor level, with the aim of sustaining gravity loads (until recent years, the school was not in a seismic area according to Italian codes). Furthermore, a $20 \mathrm{~mm}$ separation joint was introduced between body A and B. Therefore, it is reasonable to consider two substructures that behave separately under horizontal actions. Here, only body $\mathrm{A}$ is taken into consideration for the sake of conciseness.

Body A is geometrically regular with equally distributed mass, except for the large openings at the centre of the first floor of the three walls parallel to the $x$-direction, which are part of a corridor giving access to the building. A main corridor of access to classrooms is located between walls $x-1$ and $x-2$ (Figure 5). Wall thicknesses are reported in Table 1 .

A FE model consisting of 6304 triangular elements, 618 beams and 3627 nodes is used to perform the proposed homogenised

\begin{tabular}{lcccccc}
\hline Storey & \multicolumn{6}{c}{ Walls thickness: cm } \\
\cline { 2 - 7 } & $x-1$ & $x-2$ & $x-3$ & $y-1$ & $y-2$ & $y-3$ \\
\hline 1 & 60 & 45 & 60 & 60 & 45 & - \\
2 & 50 & 45 & 50 & 50 & 45 & 45 \\
3 & 45 & 30 & 45 & 45 & 30 & 30
\end{tabular}

Table 1. Entire masonry building subjected to horizontal actions

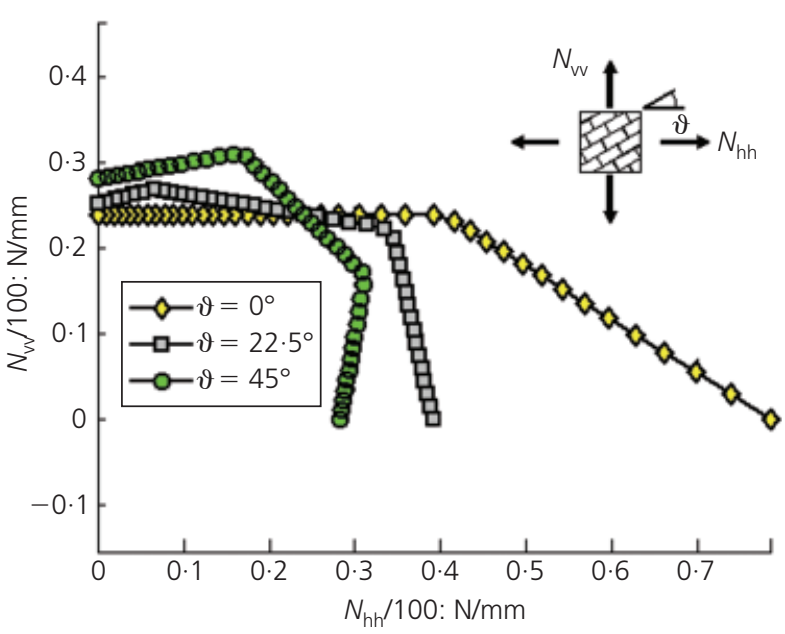

(a)

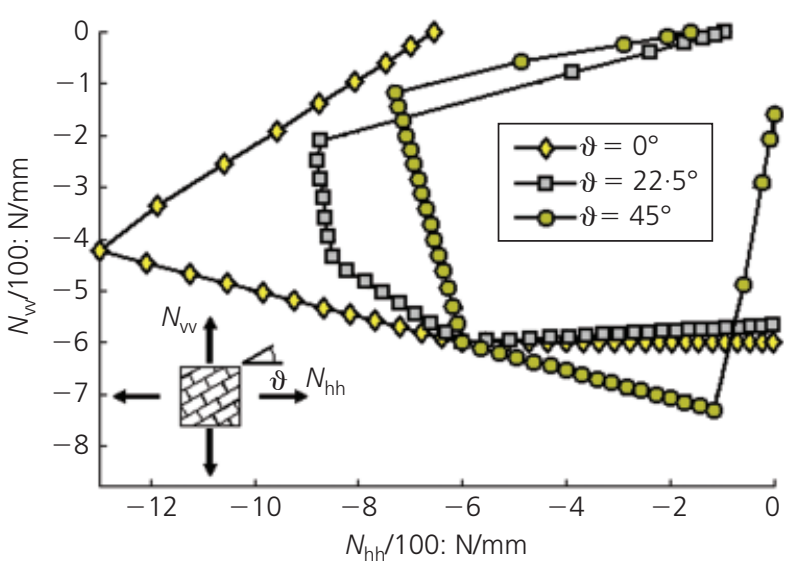

(b)

Figure 6. In-plane failure surface sections used for structural homogenised simulations. In-plane failure surfaces at different orientations of the bed joint with respect to external membrane load: (a) tension regime and (b) compression regime

\begin{tabular}{|c|c|c|c|c|c|}
\hline \multicolumn{5}{|c|}{ Joint } & Brick \\
\hline Cohesion c: $\mathrm{N} / \mathrm{mm}^{2}$ & $\begin{array}{c}\text { Tensile strength } \\
f_{\mathrm{t}}: \mathrm{N} / \mathrm{mm}^{2}\end{array}$ & $\begin{array}{c}\text { Compressive strength } \\
f_{\mathrm{c}}: \mathrm{N} / \mathrm{mm}^{2}\end{array}$ & $\begin{array}{c}\text { Friction angle } \\
\Phi_{1} \text { : deg }\end{array}$ & $\begin{array}{c}\text { Shape of linearised } \\
\text { compressive cap } \Phi_{2} \text { : } \\
\text { deg }\end{array}$ & $\begin{array}{c}\text { Compressive strength } \\
f_{\mathrm{c}}: \mathrm{N} / \mathrm{mm}^{2}\end{array}$ \\
\hline $0 \cdot 2$ & $0 \cdot 2$ & 5 & 35 & 60 & 30 \\
\hline \multicolumn{6}{|c|}{$\begin{array}{l}\text { Table 2. Entire masonry building subjected to horizontal actions. } \\
\text { Mechanical characteristics assumed for joints and bricks. For } \\
\text { joints, a linearisation of the Lourenço-Rots failure criterion } \\
\text { (Lourenço and Rots 1997) was adopted (details can be found } \\
\text { also in Milani et al., 2006a) }\end{array}$} \\
\hline
\end{tabular}


limit analysis (Figure 4(a)) under a static equivalent seismic load directed along the $x$-direction. Rigid-plastic beam elements were used to simulate steel beams (IPE 200) corresponding to the first floors under walls $y-3$; truss elements were used to model $\mathrm{RC}$ ring beams corresponding to floor levels (section $30 \times 30$, concrete compressive strength $f_{\mathrm{c}}=25 \mathrm{MPa}$ with typical reinforcement $4 \varnothing 16$ steel $\mathrm{FeB} 44 \mathrm{~K}$ (DM, 1996; OPCM, 2005). The results obtained with the homogenised FE limit analysis model (i.e. failure shear at the base and failure mechanism) are compared with a standard FE elastic-perfectly plastic analysis conducted by means of commercial FE software (Strand 7). The analysis was performed using a mesh of 3152 four-node shell elements supposing masonry isotropic with a Mohr-Coulomb failure criterion. The level of refinement of this second mesh is comparable with that of the limit analysis, considering that here quadrilateral elements are used.

In the standard elasto-plastic approach, for masonry, a cohesion $c$ equal to $0 \cdot 12 \mathrm{~N} / \mathrm{mm}^{2}$ and friction angle $\Phi=\tan ^{-1}(0 \cdot 4)$ are
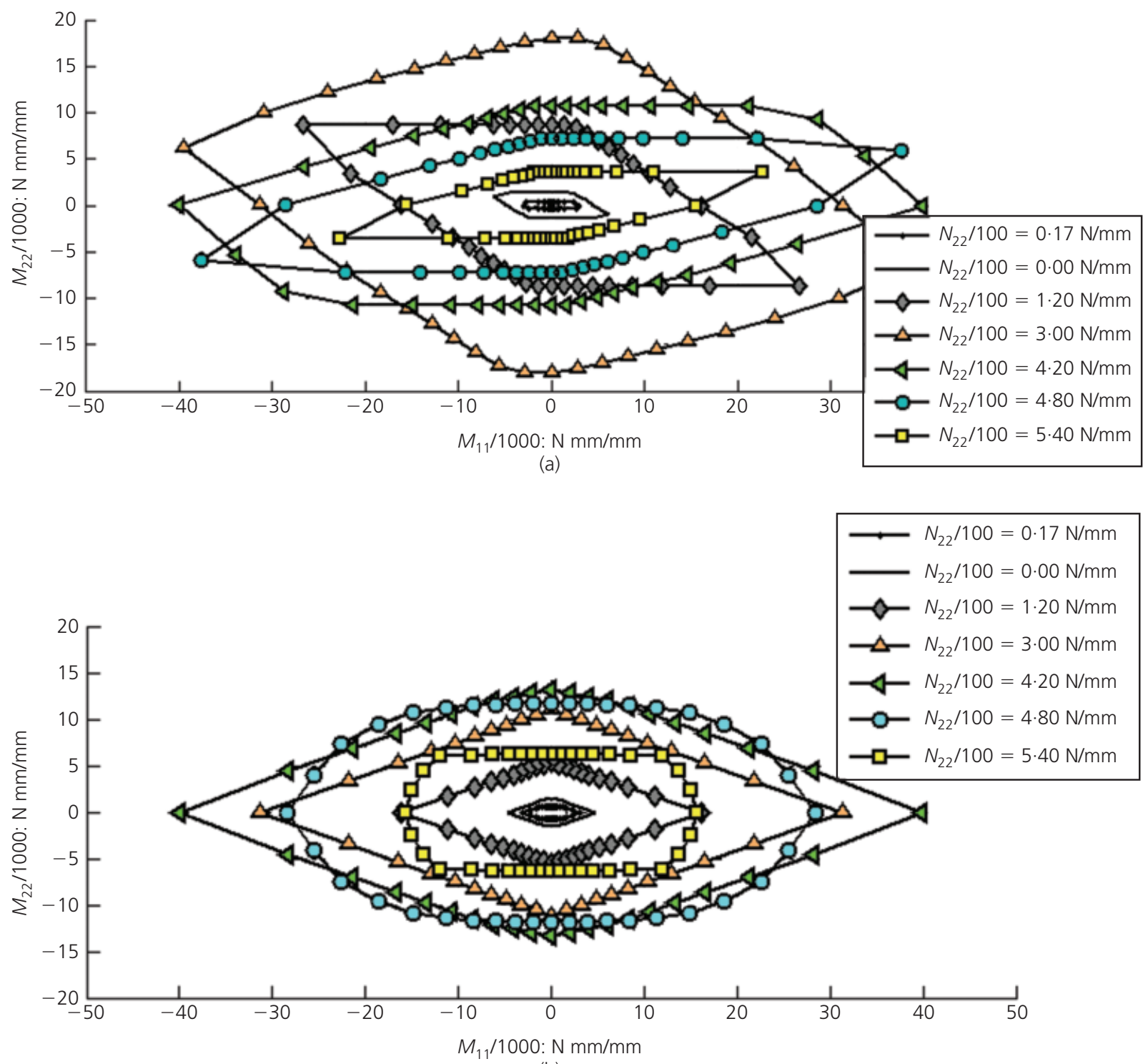

(b)

Figure 7. Out-of-plane failure surface sections used for the structural homogenised simulations. Out-of-plane failure surfaces at increasing membrane vertical pre-compression: (a) horizontal/ vertical bending moments and (b) horizontal bending moment and torsion 
adopted for the simulations, in agreement with the Italian code (OPCM, 2005). In order to compare the proposed homogenised limit analysis procedure with a standard FE model, a linearised Lourenço-Rots (see Lourenço and Rots (1997) and also Milani et al. (2006a) for a detailed description of the model) failure criterion for joints is adopted for the homogenisation approach, whereas a cut-off failure criterion in compression is assumed for units (see Table 2). While the two models are obviously incomparable since masonry performs somewhat differently with respect to a simple isotropic material, a tensile strength equal to $0 \cdot 2 \mathrm{~N} / \mathrm{mm}^{2}$ is assumed in the simulations with $f_{\mathrm{t}}=c$ (i.e. a typical value of tensile strength corresponding to mortar with mechanical properties from average to good is adopted in the limit analysis approach). In any case, a sensitivity analysis will be presented hereafter, with the aim of comparing the differences in total shear at the base obtained by changing friction/tensile properties of joints.

Figure 6 shows in-plane masonry homogenised failure surfaces in the tension-tension range (Figure 6(a)) and in the compressioncompression region (6(b)) at different orientations of the bed joint with respect to horizontal homogenised membrane action $N_{\text {hh }}$. Homogenised failure surfaces are obtained through the admissible and equilibrated model given in Section 3.

Out-of-plane masonry failure sections $M_{11}-M_{22}$ and $M_{11}-M_{12}$ at increasing (imposed) membrane in-plane vertical compression $N_{22}$ are represented in Figures 7(a) and (b), respectively. The figures show that vertical membrane load influences not only the horizontal bending moment but also the vertical one, as a consequence of the fact that bed joints also contribute to masonry vertical ultimate out-of-plane resistance. This result is in agreement with experimental evidence. Furthermore, as experimental evidence shows, there is an optimal compressive load at which failure moments reach a maximum. If this optimum point is exceeded, out-of-plane strength begins to decrease until membrane compressive failure occurs. This phenomenon is again reproduced by the model, as is shown by analysis of the results reported in Figure 7.

At a structural level, in both models, a seismic load is applied to floor $i$ by means of a horizontal distributed load of intensity $k_{i} \hat{\lambda}$ ( $k_{i}$ is a non-dimensional constant), where $\hat{\lambda}$ is the collapse load and $k_{i}$ simulates a first mode distribution (it is, indeed, equal to $z_{i} W_{i} /\left(\sum z_{i} W_{i}\right)$, where $W_{i}$ is the $i$ th floor vertical load, $z_{i}$ is the $i$ th floor distance to the ground and the summation is extended to the total number of floors (e.g. DM, 1996).

Floors, constituting small vaults made of clay bricks and supported by a framework of steel girders, are disposed parallel to the $y$-direction, corresponding to the first and second floors, and distribute vertical loads uniformly on $x$-directed walls. As a first attempt, floor stiffness is not taken into account in the numerical model, and vertical loads (which are independent of the load multiplier) are applied directly on the masonry walls corresponding to the floors. In correspondence of the third floor, a timber truss structure supports an inclined roof covering. For the sake of simplicity, the self-weight of the masonry is assumed concentrated in correspondence to the floors and added to the remaining dead loads, which are defined according to the Italian code (DM, 1996).

The kinematic FE homogenised limit analysis gives a total shear at the base of the building of $4218 \mathrm{kN}$, in good agreement with the results obtained by the standard FE procedure. In this case, the capacity curve of the building (Figure 8(a)) reaches its maximum at approximately $3800 \mathrm{kN}$.

Figure 9 shows two different views of the deformed shape obtained with the proposed limit analysis model and two details representing the out-of-plane failure of one of the walls and the behaviour of the steel beams placed at first floor level, in order to give an idea of the potential of the software developed. From a comparison of the deformed shapes at collapse provided by the standard software and the present model (compare Figure 8(b) and Figure 9), it can be argued that mixed in- and out-of-plane

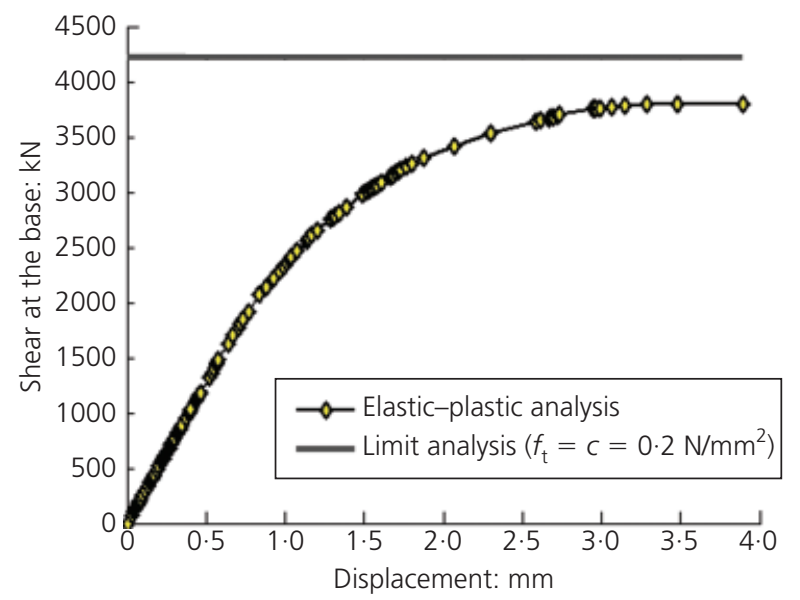

(a)

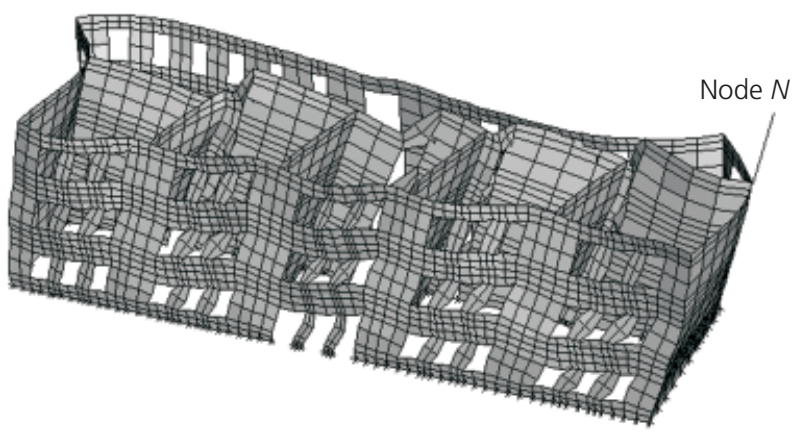

(b)

Figure 8. Masonry building subjected to horizontal actions.

Standard FE elastic plastic approach. (a) Shear at the base, node $N$ displacement curve. (b) Deformed shape at collapse 


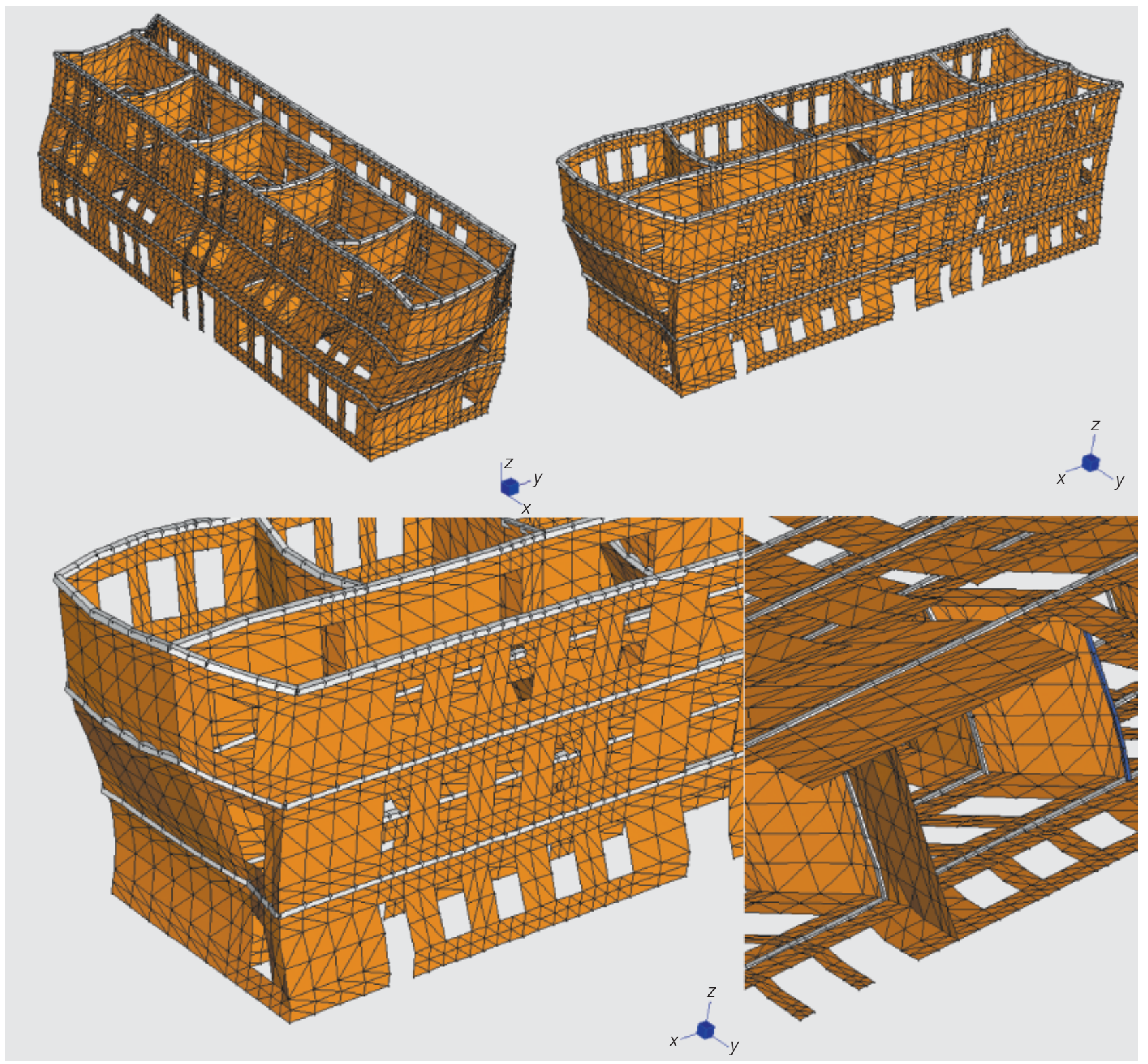

Figure 9. Masonry building subjected to horizontal actions. Two views of failure mechanism $A$ and zoomed views of the out-ofplane failure mechanism provided by the code

failure takes place and that failure is mainly concentrated along walls $x-2$ and $x-3$.

Figure 10 shows a colour patch representing the normalised plastic dissipation (values from 0 (representing no dissipation) to 1 (representing zones with the highest plasticisation)) obtained with the proposed model. Two perspective views of the entire building are presented for the sake of clarity. From an overall analysis of the output data provided by the code (Figure 9 and Figure 10), it is interesting to notice that the out-of-plane failure occurs along inclined yield lines; actual evaluation of masonry strength along directions different from the horizontal and vertical is therefore crucial. Again, it is worth emphasising that pushover analyses conducted with commercial software assuming isotropic materials are of limited interest for the analysis of $3 \mathrm{D}$ masonry structures.

Finally, a sensitivity analysis was conducted on the example at hand, assuming, for joints, a classic Mohr-Coulomb failure criterion with tension cut-off $f_{\mathrm{c}}$ equal to $\min \left\{0.05 \mathrm{~N} / \mathrm{mm}^{2}\right.$ 

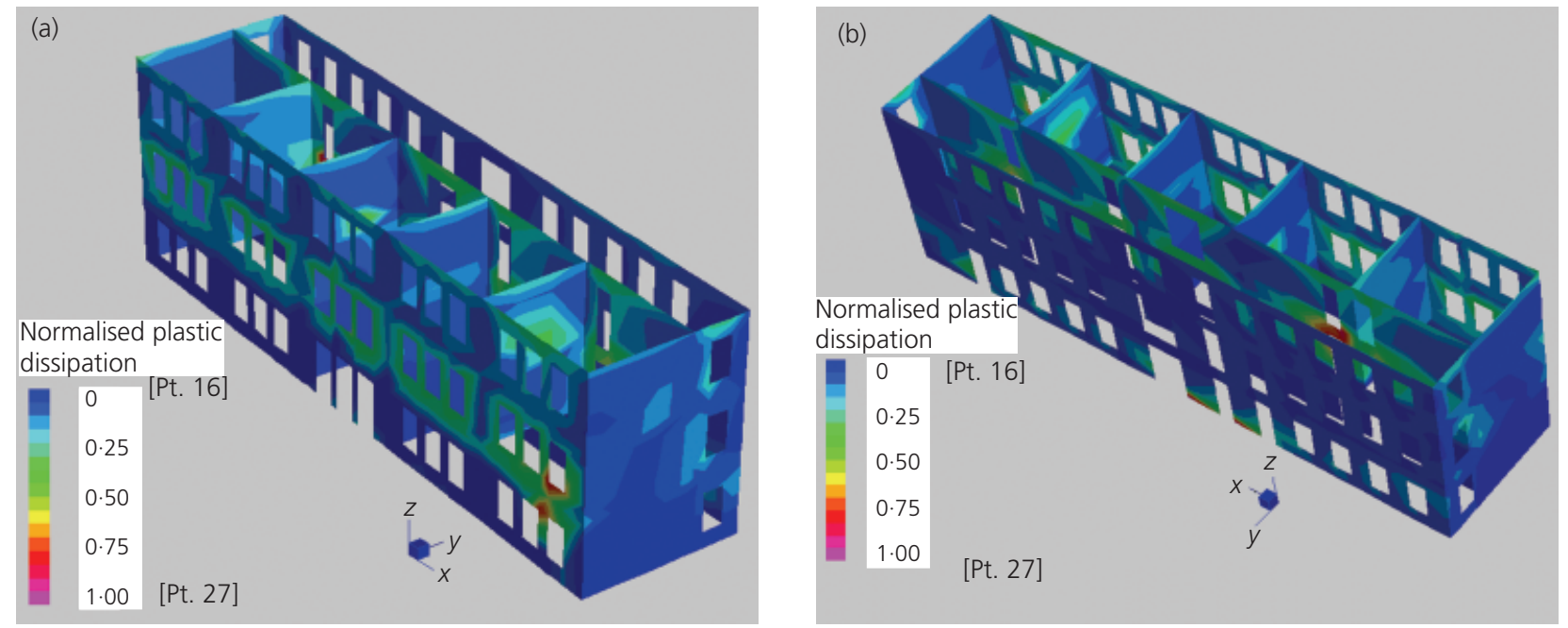

Figure 10. Masonry building subjected to horizontal actions. Two views of plastic dissipation patch on masonry elements (failure mechanism A)

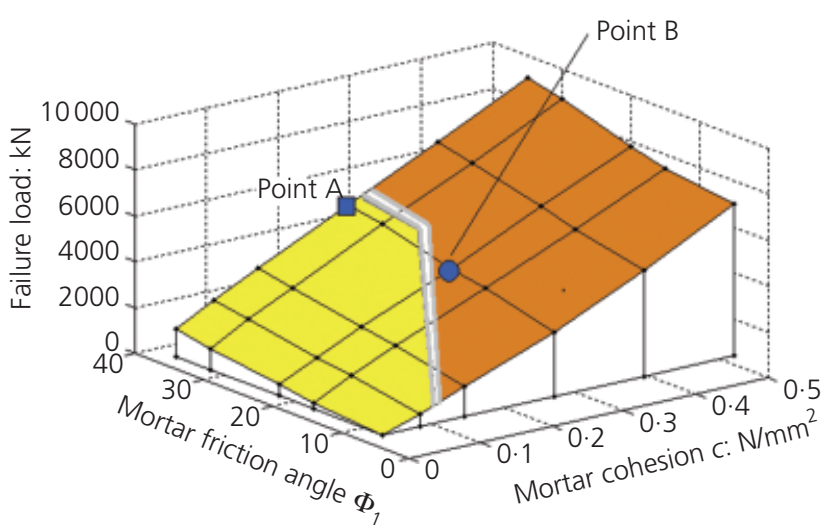

(a)

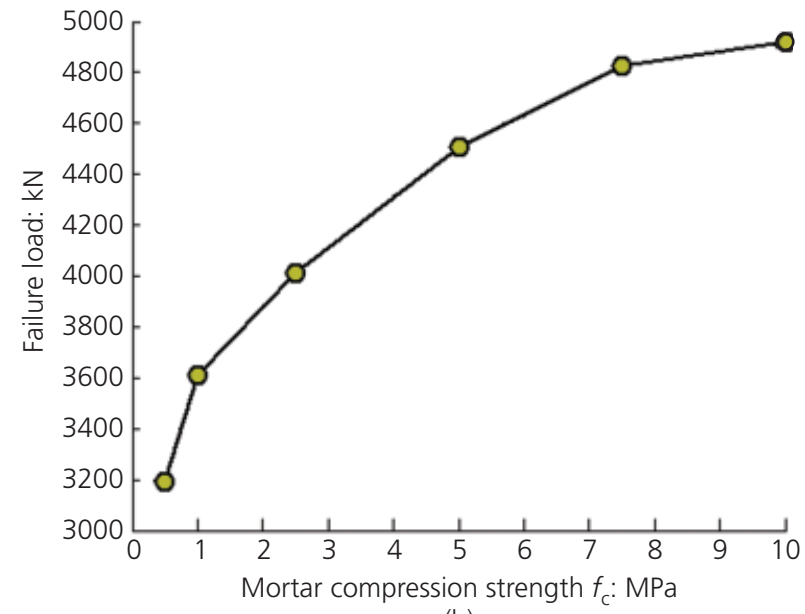

(b)

Figure 11. Masonry building subjected to horizontal actions. (a) Sensitivity analysis varying mortar cohesion and mortar friction angle and failure mechanisms patch. (b) Sensitivity analysis varying mortar compressive strength (at fixed values of other mortar mechanical properties)

$c / \tan \Phi\}$, compressive cut-off $f_{\mathrm{c}}=5 \mathrm{~N} / \mathrm{mm}^{2}$ and varying cohesion $c$ and friction angle $\Phi$ in the range $0.01-0.5 \mathrm{~N} / \mathrm{mm}^{2}$ and $5-35^{\circ}$. For bricks, a limited compressive strength equal to $30 \mathrm{~N} / \mathrm{mm}^{2}$ is also assumed.

Figure 11(a) shows the failure load of the structure with varying mortar cohesion and friction angle. From a detailed analysis of such sensitivity results, two different failure mechanisms can roughly be distinguished, labelled as failure mechanism A and B. The intervals in which they take place are indicated schematically in Figure 11(a) with different colours. In particular, mechanism A, reported in Figure 9, corresponds to an in-plane failure of walls $x-2$ and $x-3$ combined with an out-of-plane failure of walls $y-1$. On the other hand, mechanism $\mathrm{B}$, reported in Figure 12 , combines a shear failure of wall $x-2$ concentrated on the second storey and overturning of walls $y-1$. For the sake of 
FE homogenised limit analysis model Milani and Lourenço completeness, Figure 13 shows the plastic dissipation patch on masonry elements corresponding to mechanism B simulations. From a comparison of deformed shapes at collapse and plastic dissipation corresponding to the numerically evaluated failure mechanism provided in case A and B by the FE model, it can be clearly stated that the choice of mechanical properties of the constituent materials is crucial for correct and realistic evaluation of the overall behaviour of a building.

Figure 11(b) shows some results of a sensitivity analysis conducted with varying mortar compressive strength over a wide range. In particular, total shear at the base is represented with varying mortar $f_{\mathrm{c}}$ from 10 to $0.5 \mathrm{~N} / \mathrm{mm}^{2}$ while keeping all the other values constantly equal to those reported in Table 2 . It is worth mentioning that, while there is little influence of the compressive strength of the bricks on the failure loads (since in the model, which is a 2D approach, masonry compressive strength depends solely on the geometry of the cell and mortar compressive strength until the compressive strength of the bricks is greater than that of the mortar (see Milani et al. (2006a) for a detailed discussion of this limitation)) some meaningful variations may be noticed when reducing the mortar compressive strength. In fact, a great amount of resistance to horizontal actions is due to the contribution of the three walls parallel to $x$-axis (which are mainly subjected to in-plane actions) and, since masonry compressive strength influences pier resistance, a reduction of $f_{\mathrm{c}}$

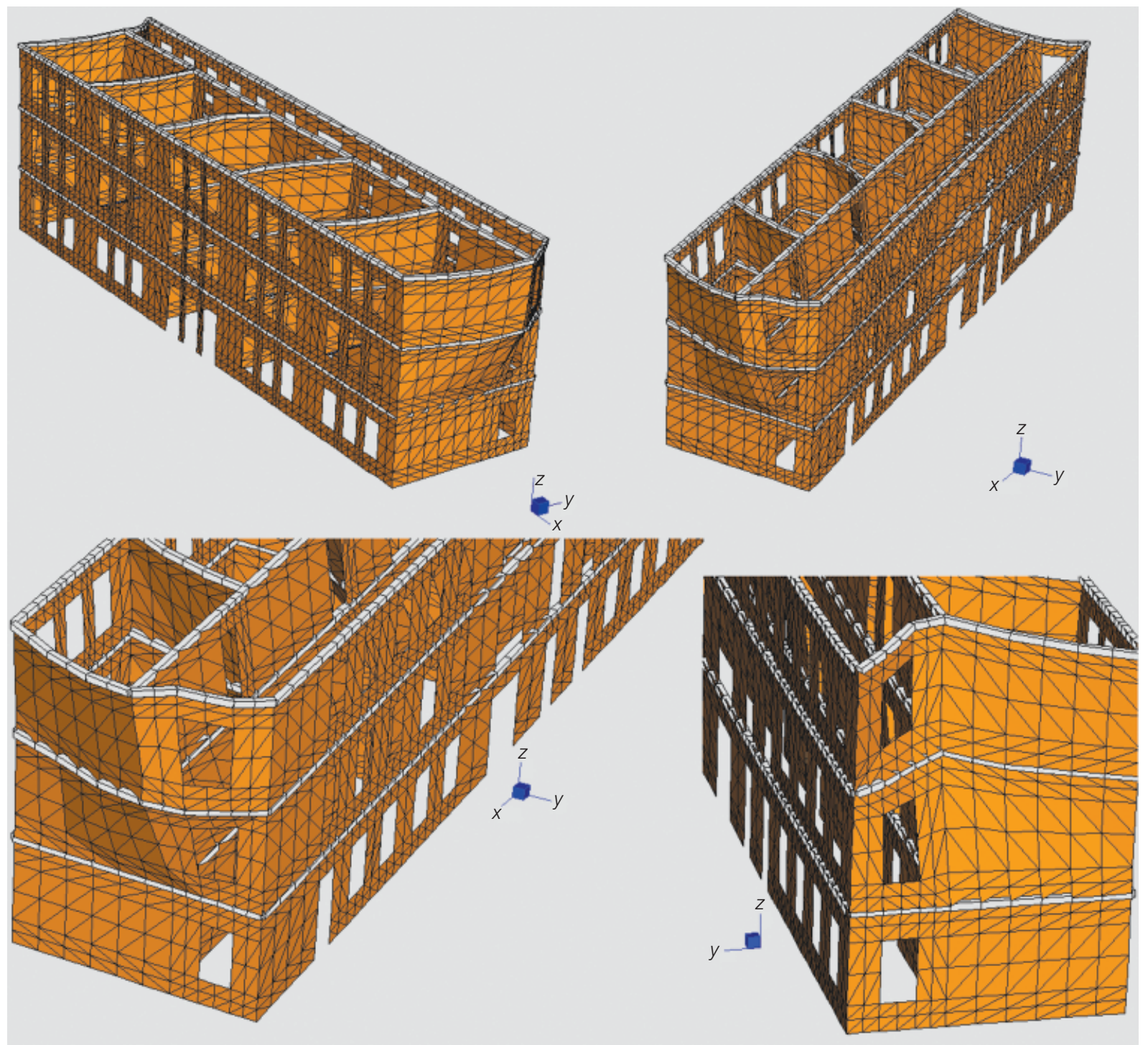

Figure 12. Masonry building subjected to horizontal actions. Two views of failure mechanism $B$ and zoomed views on the out-ofplane failure mechanism provided by the code. 


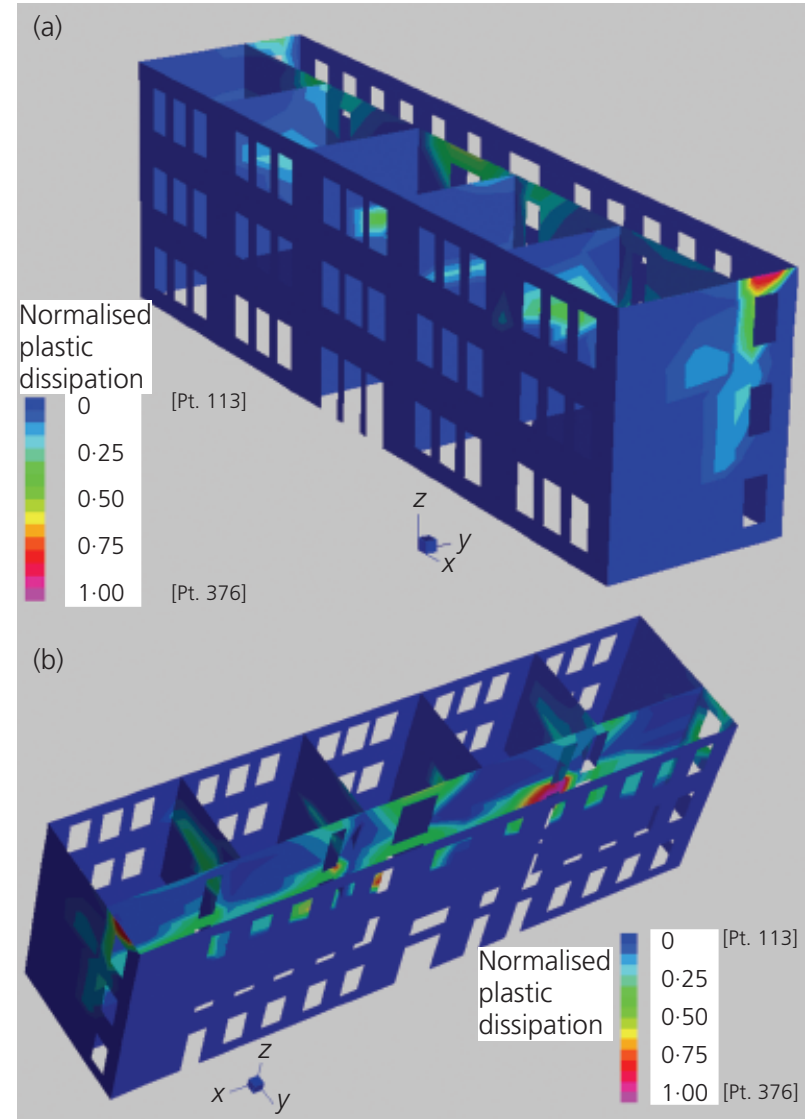

Figure 13. Masonry building subjected to horizontal actions. Two views of plastic dissipation patch on masonry elements (failure mechanism B).

results indirectly in a reduction of the total shear at the base withstood by the building. Obviously, for high values of $f_{\mathrm{c}}$, the increase in failure load is minimal, meaning that piers collapse mainly for shear actions. On the contrary and as expected, for very low values of $f_{\mathrm{c}}$, a meaningful decrease of the failure load is observed.

\section{Conclusions}

A 3D FE upper bound limit analysis code based on homogenisation has been presented. The software is based on a plate and shell discretisation of masonry piers and spandrels. The possible presence of $1 \mathrm{D}$ beams is modelled by means of two-node rigid beam (or truss) elements. Homogenised masonry failure surfaces are utilised in the software. They are obtained by sub-dividing the elementary cell along its thickness into several layers. For each layer, fully equilibrated stress fields are assumed, adopting polynomial expressions for the stress tensor components in a finite number of sub-domains. The structural model allows plastic dissipation for in-plane actions on triangular elements and interfaces, whereas out-of-plane yield lines are concentrated only at the interfaces between contiguous elements.

To validate the FE model proposed, a relevant 3D structural example (a masonry school subjected to horizontal actions) was treated. Full sensitivity analyses and a comparison with results obtained with commercial elasto-plastic software have been presented, and indicate good performance by the model.

For all the simulations, the proposed model (also considering the homogenised failure surface evaluation) took less than 3 min on a standard PC Intel Celeron $770 \quad 1.40 \mathrm{GHz}$ equipped with 2 GB RAM. This processing time is negligible compared with standard FE incremental procedures.

\section{REFERENCES}

Cecchi A and Milani G (2008) A kinematic FE limit analysis model for thick English bond masonry walls. International Journal of Solids and Structures 45(5): 1302-1331.

DM (Decreto Ministeriale) (1996) DM 16/01/1996 (G.U. 5-21996, N. 29): Technical norms relative to 'general criteria for the safety assessment of structures and loads' (Norme tecniche relative ai 'Criteri generali per la verifica di sicurezza delle costruzioni, e dei carichi e sovraccarichi') (in Italian). DM, Rome.

Giuffrè A (1993) Safety and Conservation of Historical Centers: The Ortigia Case. Laterza Press, Rome (in Italian).

Heyman J (1969) The safety of masonry arches. International Journal of Mechanical Sciences 11(4): 209-224.

Krabbenhoft K, Lyamin AW, Hjiaj M and Sloan SW (2005) A new discontinuous upper bound limit analysis formulation. International Journal for Numerical Methods in Engineering 63(7): 1069-1088.

Lourenço PB (2002) Computations of historical masonry constructions. Progress in Structural Engineering and Materials 4(3): 301-319.

Lourenço PB and Rots J (1997) A multi-surface interface model for the analysis of masonry structures. ASCE Journal of Engineering Mechanics 123(7): 660-668.

Lourenço PB, De Borst R and Rots J (1997) A plane stress softening plasticity model for orthotropic materials. International Journal for Numerical Methods in Engineering 40(21): 4033-4057.

Milani G, Lourenço PB and Tralli A (2006a) Homogenised limit analysis of masonry walls. Part I: failure surfaces. Computers \& Structures 84(3-4): 166-180.

Milani G, Lourenço PB and Tralli A (2006b) Homogenised limit analysis of masonry walls. Part II: structural examples. Computers \& Structures 84(3-4): 181-195.

Milani G, Lourenço PB and Tralli A (2006c) Homogenisation approach for the limit analysis of out-of-plane loaded masonry walls. ASCE Journal of Structural Engineering 132(10): 1650-1663.

Milani G, Lourenço PB and Tralli A (2007) 3D homogenized limit analysis of masonry buildings under horizontal loads. Engineering Structures 29(10): 3134-3148.

Munro J and Da Fonseca AMA (1978) Yield-line method by finite elements and linear programming. Structural Engineer 56B(2): $37-44$. 
OPCM (Ordinanza del Presidente del Consiglio dei Ministri) (2003) OPCM 3274 (20/03/2003): First elements concerning general criteria for the seismic classification of the national territory and technical norms for structures in seismic zone (Primi elementi in materia di criteri generali per la classificazione sismica del territorio nazionale e di normative tecniche per le costruzioni in zona sismica) (in Italian). OPCM, Rome.

OPCM (2005) OPCM 3431/05 (09/05/2005): Further modifications and integrations on OPCM 3274/03 (Ulteriori modifiche ed integrazioni all'OPCM 3274/03) (in Italian). OPCM, Rome.
Sinha BP (1978) A simplified ultimate load analysis of laterally loaded model orthotropic brickwork panels of low tensile strength. Structural Engineer 56B(4): 81-84.

Sloan SW and Kleeman PW (1995) Upper bound limit analysis using discontinuous velocity fields. Computer Methods in Applied Mechanics and Engineering 127(1/4): 293-314.

Suquet P (1983) Analyse limite et homogeneisation. Comptes Rendus de l'Academie des Sciences, Series IIB Mechanics 296: $1355-1358$.

\section{WHAT DO YOU THINK?}

To discuss this paper, please email up to 500 words to the editor at journals@ice.org.uk. Your contribution will be forwarded to the author(s) for a reply and, if considered appropriate by the editorial panel, will be published as a discussion in a future issue of the journal.

Proceedings journals rely entirely on contributions sent in by civil engineering professionals, academics and students. Papers should be $2000-5000$ words long (briefing papers should be 1000-2000 words long), with adequate illustrations and references. You can submit your paper online via www.icevirtuallibrary.com/content/journals, where you will also find detailed author guidelines. 